\title{
ENGINEERING GEOLOGICAL ASPECTS FOR THE MICROZONATION OF THE CITY OF VOLOS, GREECE
}

\author{
Antoniou A. A. ${ }^{1}$ and Tsiambaos G. ${ }^{1}$ \\ ${ }^{1}$ National Technical University of Athens, School of Civil Engineering, Department of Geotechnical \\ Engineering, 9 Iroon Polytechniou street, 15780 Zografou, Athens, Greece
}

\begin{abstract}
The city of Volos located at the foot of the Peninsula of Pelion at Central Greece experienced several strong earthquakes during the previous century. The engineering geological conditions of the city have been analyzed using a relational geotechnical database management system, while the city subsoil has been grouped into five geotechnical units. The maps showing the contours of the depth to bedrock head and the ground zoning against seismic hazard were compiled through GIS. For the compilation of the latter map, a set of unified classification criteria was proposed based on the Greek Seismic Code (EAK 2000).
\end{abstract}

Key words: seismic microzonation, GIS, engineering geological mapping, geotechnical data, Volos

\section{Introduction}

The city of Volos, the capital of the Magnesia prefecture, is located at the foot of the Peninsula of Pelion at Central Greece and constitutes an important commercial harbor and export centre. The urban development of the city was primarily based on economic and social determinants such as the establishment of the industrial estate, the upgrading of the port and the rapid growth of tourism. The broader area of the city is located in a narrow strip of the Pagasitikos gulf basin and west of the Pelion mountain range. Three main streams run through the region i.e. Xerias, Kravsidonas and Anavros (Fig. 1).

As regarding seismicity of the broader area, which constitutes the main natural hazard for the city, medium to strong earthquakes are closely related to the active fault zones crossing the Magnesia area and Pagasitikos gulf.

Due to this seismic activity, the city of Volos presents a high risk against earthquake, while severe structural damage has been occurred in the past. It must be noted that the engineering geological environment and the intense geodynamic processes were not taken into account for the urban planning of the city. The aim of this work was to collect and evaluate the data referred to engineering geological and geotechnical conditions of the area and to define the earthquake hazard zones in the city of Volos. This type of zonation is commonly referred to the preliminary phase of the seismic microzonation and seismic risk analysis and mitigation strategy for an urban area.

\section{Geological setting}

The bedrock of the city belongs to the Pelagonian geotectonic zone. It consists, according to the ge- 


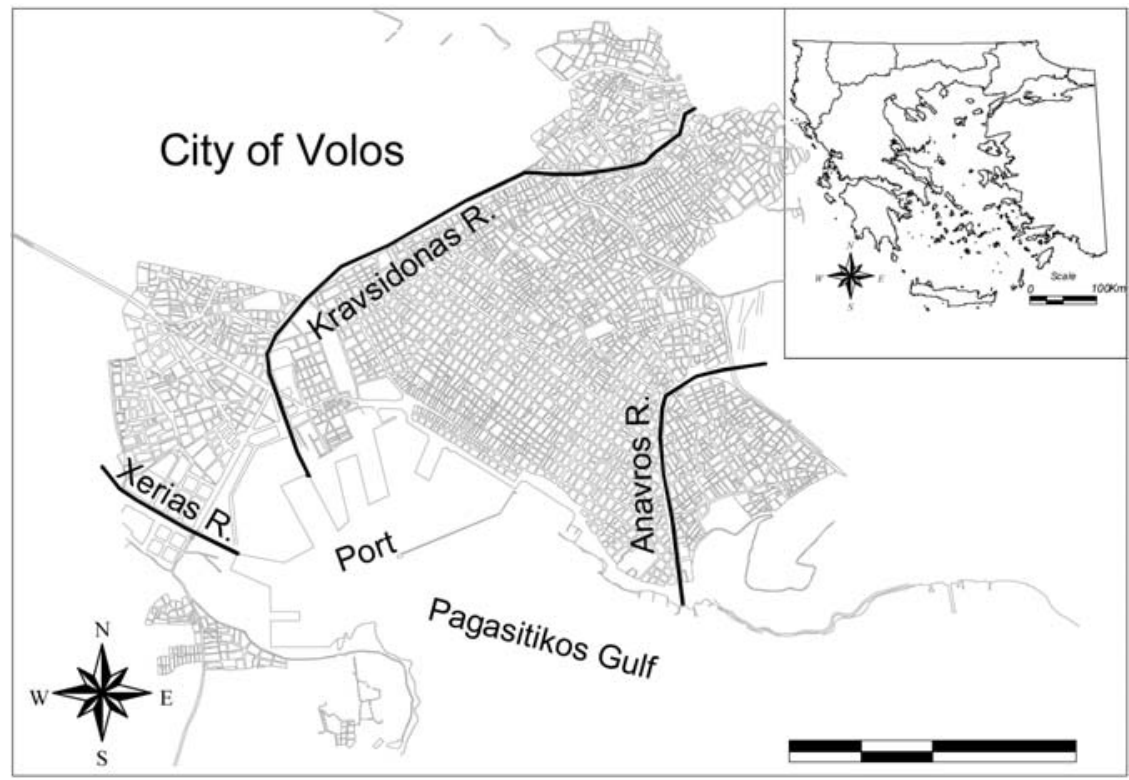

Fig. 1: General reference map of the city of Volos.

ological map of Greece of scale 1:50.000 (Katsikatsos et al., 1986) mainly of:

- Neopaleozoic to Middle Triassic schists, prasinites, quartzites and phyllites with intercalations of marbles and cipolins, of a total thickness of $800 \mathrm{~m}$. These formations outcrop at the eastern part of the broader area of the city.

- Middle Triassic to Upper Jurassic marbles, with schists and metabasite rocks intercalations, which are intensively folded and recognized. They have a total thickness of $800 \mathrm{~m}$ and dominate at the north- eastern, south-eastern and south-western part.

- Amphibolitic schists accompanied by crystalline limestones and marbles, belonging to the Eohellenic (pre-upper Cretaceous) tectonic nappe. They have a maximum thickness of $300 \mathrm{~m}$ and cover the area north of the city.

- Neogene deposits, such as red clay, silt and clayey-sandy material of low cohesion with breccia and conglomerate intercalations with a maximum thickness of $100 \mathrm{~m}$, outcrop west of the city.

- The quaternary deposits are of great extent dominating at the Volos city. They are fluvial-torrential terraces (mainly loose conglomerates) covering the western part, and plain deposits (consisting of sand, silt and clay with low percentage of coarse grained material) which cover the central part of the city. Pleistocene and Holocene scree and talus cones develop at places in the eastern city borders.

\section{Seismological aspects}

The geomorphology of Thessaly is mainly controlled by two systems of normal faults. The first NW-SE trending fault-system formed the basins of Larissa and Karditsa and probably controlled the orientation of coastline (Goldsworthy et al., 2002). The second system, striking E-W developed 
in numerous fault zones in Thessaly district, which have formed new small grabens and offset the plio-quaternary deposits (Caputo,1990), This phase is very important for the tectonic evolution of the whole Thessaly region and also the Volos area, during which new faults have been formed and the recent morphology has been established. The focal mechanism of strong earthquakes and microearthquakes indicates a N-S trending extension along the E-W striking faults, the same also deduced by the tectonic analysis of recent faults (Papazachos et al. 1983, Hatzfeld et al, 1999).

The region experienced several strong earthquakes during historical time, such as in 743 and 1773 as well as in the recent time (Papazachos and Papazachou, 1989). In more detail, on April 19, 1955 an earthquake of $\mathrm{M}_{\mathrm{s}}=6.2$ caused extensive damage in the area of Volos. Its epicenter was located at Lechonia (less than $50 \mathrm{~km}$ from the city of Volos). Damage was observed in the Magnesia prefecture, where 449 buildings were destroyed, 7609 suffered serious damage and 3540 lighter damage. Most of these structural damages were observed in the villages of Pelio mountain, where buildings were founded on the loose mantle of weathering, on steep slopes suffering landslide phenomena. The extended damage is also attributed to the weakening of the buildings by the prior Sophades earthquake $\left(\mathrm{M}_{\mathrm{s}}=7.0\right)$ of 30 April 1954 .

Moreover, on March 8, 1957 an earthquake of $\mathrm{M}_{\mathrm{s}}=6.8$ caused serious damage in the prefectures of Magnesia, Larissa, Karditsa and Trikala. Seven minutes before the main shock a large foreshock $\left(M_{s}=6.5\right)$ occurred, the consequence of which cannot be distinguished from those of main shock.

Finally, on July 9, 1980 an earthquake of $\mathrm{M}_{\mathrm{s}}=6.5$ caused severe damage in the prefectures of Magnesia, Phthiotida and Larissa. The epicenter was located at Almyros town, approximately 50km from the city of Volos. In total 5222 buildings were destroyed, 14726 suffered serious damage and 10688 light damage. In Nea Agchialos town, small ground fissures with an east-west direction were observed. These fissures were considered as shallow traces of small faults which were generated in the superficial deposits striking parallel to the main seismic fault which was not observed on the surface.

\section{Geotechnical investigation and ground conditions}

In order to determine the geotechnical characteristics of the subsoil of the city of Volos data collected from about 120 sampling boreholes and trial pits. The location of the investigations sites are shown in Fig. 2.

The information was implemented, after a thorough inspection and modification to standardize the terminology, in a geotechnical database under the name HelGeoRDaS (Hellenic Geotechnical Relational Database management System). The objects that are included in the database are:

- Tables: Seven primary tables and several auxiliary ones were formed and all are related with each other in the common field "code of geotechnical research".

- Queries: The built in queries are retrieving data from one or more tables.

- Forms: For the easy implementation of data seven forms were built, one for each main table.

An extensive description of the system can be found in Antoniou et al (2001, 2008).

Moreover, the geotechnical database cites geographical information (e.g. coordinates), therefore the import of topology that concerns the territorial information, has been achieved with the connection of programs MS Access and ArcInfo of ESRI via Structured Query Language (SQL).

The majority of the geotechnical investigations were executed mainly for the construction of public buildings and engineering works at the port of Volos. Due to their vicinity with the coast, the 


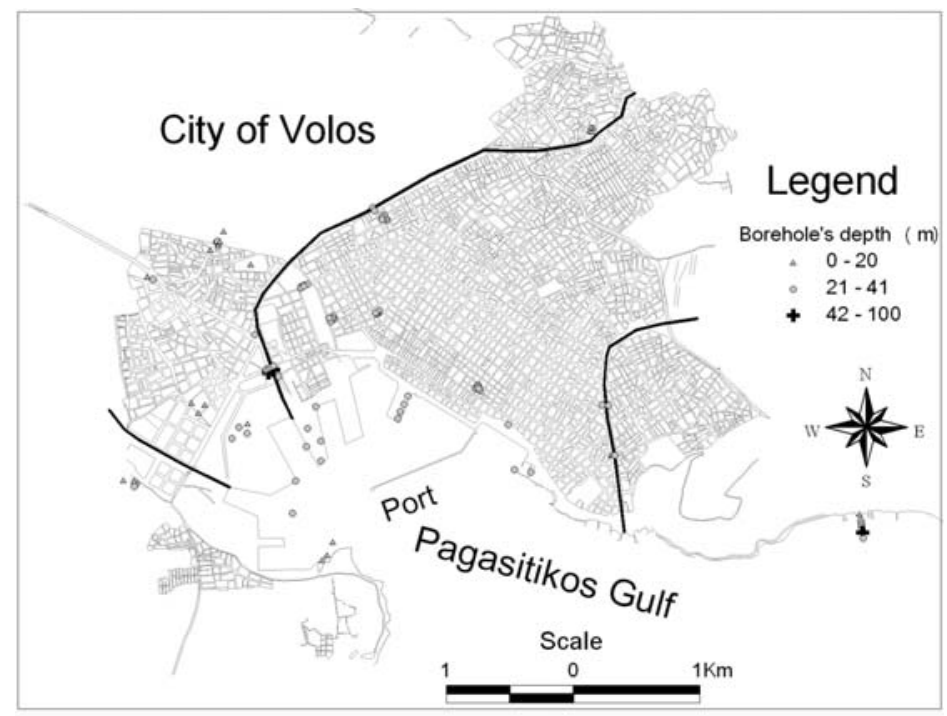

Fig. 2: Geotechnical investigation sites at the city of Volos.

Table 1. Description of geotechnical units with the range of measured parameters

\begin{tabular}{|c|l|c|}
\hline Unit & Soil classification & Physical and mechanicals properties \\
\hline I & Earth fills & \\
\hline II & ML, CL, OH & $\begin{array}{r}\mathrm{LL}=40-60, \mathrm{PI}=20-25, \mathrm{w}=20-40 \% \\
\mathrm{c}_{\mathrm{u}}=40 \mathrm{KPa}, \mathrm{N}_{\mathrm{SPT}}=1 \text { to } 10\end{array}$ \\
\hline IIIa & CL, ML & $\begin{array}{r}\mathrm{LL}=20-40, \mathrm{PI}=5-20, \mathrm{w}=20-30 \% \\
\mathrm{c}_{\mathrm{u}}=15-80 \mathrm{KPa}, \mathrm{N}_{\mathrm{SPT}}=2 \text { to }>50\end{array}$ \\
\hline IIIb & SC, SM, SG, GM & $\mathrm{LL}=20-40, \mathrm{PI}=5-10, \mathrm{w}=20 \%, \mathrm{~N}_{\mathrm{SPT}}=15$ to $>50$ \\
\hline IV & GW, GM, GC, GP & $\begin{array}{c}\mathrm{LL}=20-40, \mathrm{PI}=5 \\
\mathrm{~N}_{\mathrm{SPT}}=15 \text { to }>50\end{array}$ \\
\hline V & Bedrock & \\
\hline
\end{tabular}

depth of sampling boreholes was usually greater than $20 \mathrm{~m}$ and in some cases over $140 \mathrm{~m}$, including the execution of Standard Penetration Tests (SPT).

To describe in detail the engineering geological conditions of the urban area, the soil formations were grouped into five individual geotechnical units, based on the evaluation of the existing geotechnical database taking into account the origin and age as well as the physical and mechanical characteristics of soil formations. Table 1 summarizes the physical and mechanical properties of the geotechnical units, as described hereafter:

Unit I: Earth fill materials which cover the major part of the city with a maximum thickness of $3 \mathrm{~m}$.

Unit II: Very loose to soft grey silt of low plasticity (ML) with intercalations of soft grey to brown clay of low plasticity (CL) or organics of high plasticity $(\mathrm{OH})$. This unit underlies the backfill ma- 


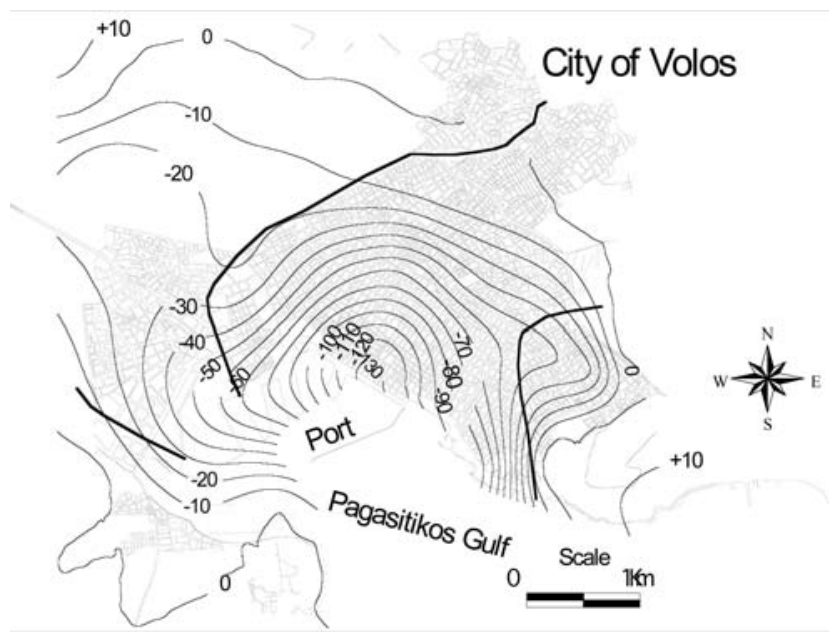

Fig. 3: Contour map showing the depth to bedrock head.

terials and covers mainly the coastal line and extends for about $200 \mathrm{~m}$ towards the central part of the city. Its maximum thickness is $30 \mathrm{~m}$.

Unit III: Mixed phases of alluvial deposits which underlie directly unit I (at the central part of the city) or unit II (at the coastal area). Moreover, this unit can be subdivided to:

Unit IIIa (fine grained materials): Cohesive to stiff clay of low plasticity (CL) or silts of low plasticity (ML). The maximum thickness is $20 \mathrm{~m}$.

Unit IIIb (coarse grained materials): Medium dense clayey to silty sand (SC, SM) or dense sandy gravel (SG) or silty gravel (GM) with a maximum thickness of $30 \mathrm{~m}$.

Unit IV: Dense to very dense clayey to silty gravel well to poor graded (GW, GM, GC, GP). This unit underlies directly unit I or III at the northern part of the city. The maximum thickness is about $25 \mathrm{~m}$ and locally in the coastal area exceeds $60 \mathrm{~m}$.

Unit V: This unit refers to bedrock and consists of schists, crystalline limestones and marbles. The bedrock outcrops at the surrounded hills and at Pelion mountain and usually develops a thick mantle of weathering.

The evaluation of the processed geotechnical data, led to the compilation of an engineering geological map (Fig. 3) showing the depth to bedrock head with contours at $10 \mathrm{~m}$ intervals. The maximum depth in the coastal area is greater than $130 \mathrm{~m}$ while to the north east and west part of the city the bedrock crops out.

\section{Ground zoning for earthquake hazard}

The available geological and geotechnical data, obtained from data retrieval options using HelGeoRDaS, as well as in situ observations, were evaluated with reference to the ground categories provided by the Greek Seismic Code (EAK 2000, Table 2).

Table 3 defines four zones for the city of Volos, each zone described in terms of the basic engineering geological characterisitics, such as lithology, mechanical behaviour, stiffness, thickness etc (Marinos et al., 2001). Based on the aforementioned ground zoning, an engineering geological zoning map referring to earthquake hazard was compiled and presented in Fig. 4. 
Table 2. Ground categories according to the Greek seismic code (EAK).

\begin{tabular}{|c|c|}
\hline Category & Description \\
\hline \multirow{3}{*}{ A } & Hard or soft rock formations, with no intense weathering \\
\hline & Layers of dense granular material with little silt or clay, and thickness over $70 \mathrm{~m}$ \\
\hline & Layers of very stiff overconsolidated clay, less than $70 \mathrm{~m}$ thick \\
\hline \multirow{3}{*}{ B } & Highly weathered rock \\
\hline & $\begin{array}{l}\text { Layers of granular material of medium density and thickness over } 5 \mathrm{~m} \text { or of high den- } \\
\text { sity and thickness over } 70 \mathrm{~m}\end{array}$ \\
\hline & Layers of hard overconsolidated clay more than $70 \mathrm{~m}$ thick \\
\hline $\mathrm{C}$ & $\begin{array}{l}\text { Layers of granular material of low relative density and thickness over } 5 \mathrm{~m} \text { or of } \\
\text { medium density and thickness over } 70 \mathrm{~m}\end{array}$ \\
\hline D & Soft clays with plasticity index Ip $>50$; thickness $>10 \mathrm{~m}$ \\
\hline \multirow{6}{*}{$\mathbf{X}$} & Loose silty-sand soils under ground water level liquefaction risk \\
\hline & Soils close to identified active faults \\
\hline & Steep slopes with loose scree \\
\hline & $\begin{array}{l}\text { Loose granular soils or soft clayey-silty soils prone to dymanic consolidation or } \\
\text { strength loss }\end{array}$ \\
\hline & Recent loose earthfill, organic soils, rubble \\
\hline & Soils of category $\mathrm{C}$ in very steep slopes \\
\hline
\end{tabular}

Table 3. Description of earthquake hazard zones in the city of Volos.

\begin{tabular}{|c|l|}
\hline Zone & \multicolumn{1}{c|}{ Description } \\
\hline $\mathbf{1}$ & $\begin{array}{l}\text { Bedrock formations. Hard or soft rock including crystalline limestones, schists, marbles, } \\
\text { marls and well-cemented conglomerates. According to the Greek Seismic Code (EAK) this } \\
\text { zone corresponds to ground category A. The highly weathered mantle of these formations } \\
\text { with thickness greater than 5m compares to stiff soils formations and corresponds to ground } \\
\text { category B. Stiff or dense soils. Includes mainly debris, talus cones and conglomerates of var- } \\
\text { ious cementation, clayey sand and gravel, stiff and hard clays. According to the EAK this } \\
\text { zone corresponds to ground category A (very dense or cohesive soils) or B (looser soils with a } \\
\text { thickness greater than 5 to 10m). }\end{array}$ \\
\hline $\mathbf{2}$ & $\begin{array}{l}\text { Medium stiff or dense soils. Includes recent deposits and non-cemented debris con-sisting } \\
\text { mainly of silty-clayey soils of low strength and low to medium dense clayey sand and gravel. } \\
\text { According to the EAK, this zone corresponds to ground category B, except those with low } \\
\text { strength and low density with thickness greater than 10 -20 m which correspond to category C. }\end{array}$ \\
\hline $\mathbf{3}$ & $\begin{array}{l}\text { Coastal deposits. Includes recent loose sands and silts as well as soft clays of low to medium } \\
\text { plasticity. According to the EAK, this zone corresponds to ground category C. Loose silty- } \\
\text { sand soils under ground water level with liquefaction risk. }\end{array}$ \\
\hline $\mathbf{4}$ & $\begin{array}{l}\text { Rivers and watercourses. Includes areas along main rivers (Xerias, Kravsidonas and } \\
\text { Anavros). The limits of this zone are only indicative on the map and its exact extent should } \\
\text { result from detailed investigations, as foreseen in EAK for ground category X. }\end{array}$ \\
\hline
\end{tabular}




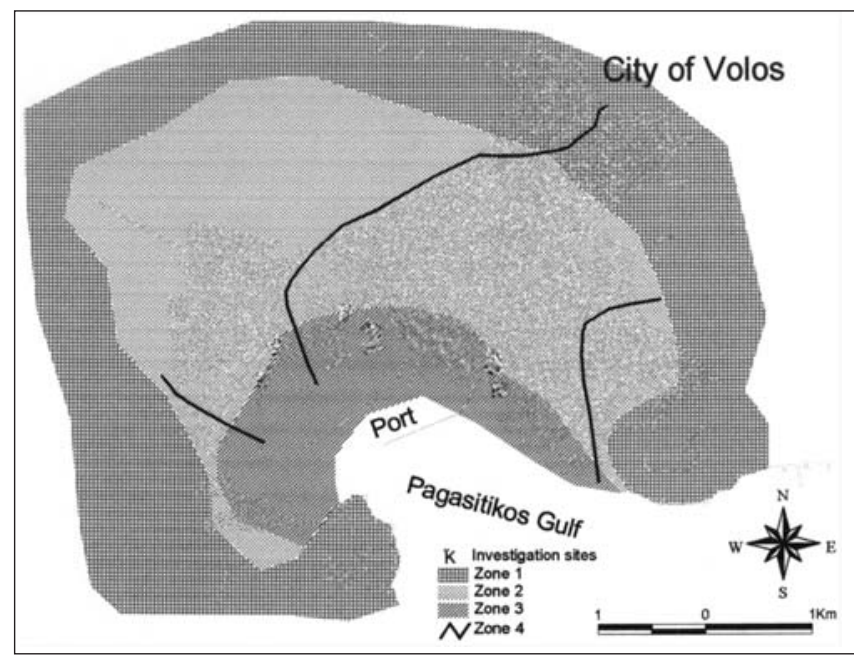

Fig. 4: Ground zoning map of Volos basin concerning earthquake hazard.

\section{Conclusions}

The engineering geological conditions of the urban area of Volos have been studied by using information derived from HelGeoRDaS geotechnical data base obtained from detailed geotechnical survey, as well as from in situ observations. In particular, the soil formations of the urban area were grouped into five geotechnical units, while thematic maps were compiled to illustrate information such as the depth to bedrock head. Moreover, an engineering geological zoning map referring to earthquake hazard was compiled with reference to the ground categories provided by the Greek Seismic code, EAK 2000. This mapping is considered appropriate for use at a preliminary local urban planning level, while more detailed geotechnical investigation is required for specific foundation works.

\section{References}

Antoniou, A.A., Papadimitriou, A.G., Tsiambaos, G. 2008. A Geographical Information System managing geotechnical data for Athens (Greece) and its use for automated seismic microzonation. Natural Hazards, 47:369-395.

Antoniou, A., Marinos, P., Kavvadas, M., Tsiambaos, G., Tsatsanifos, C. 2001. A geotechnical relational database management system In: Proceedings of the 4th Hellenic Symposium in Geotechnical Engineering and Geoenvironment. 1, 29-34.

Caputo R., 1990.Geological and structural study of the recent and active brittle deformation of the neogene- quaternary basins of Thessaly. Ph.D. thesis, Univ. of Thessaloniki, Greece, 251 p.

EAK, 2000. Earthquake Design Code, Earthquake Planning and Protection Organization, Athens (in Greek)

Goldsworthy, M., Jackson, J., Haines, A.J. 2002. The continuity of active fault systems in Greece, Geophysical Journal International, 148, 3, F596-618.

Hatzfeld, D., Ziazia, M., Kementzetzidou, D., Hatzidimitriou, P., Panagiotopoulos, D., Makropoulos, K., Papadimitriou, P., and Deschamps, A., 1999. Microseismicity and Focal Mechanisms at the Western Termination of the North Anatolian Fault and their Implications for Continental Tectonics. Geophys. J. Int., 137, 891-908. 
Katsikatsos G., Mylonakis J., Vidakis M., Hecht J and Papadeas G., 1986. Geological map of Greece scale 1:50.000, sheet "Volos". Institute of Geology and Mineral Exploration, Athens.

Marinos, P., Bouckovalas, G., Tsiambaos, G., Sabatakakis, N., Antoniou, A. 2001. Ground zoning against seismic hazard in Athens, Greece. Engineering Geology, 62, 343-356.

Papazachos, B. C., Panagiotopoulos, D. G., Tsapanos, T. M., Mountrakis, D. M. and Dimopoulos, G. Ch., 1983. A study of the 1980 summer seismic sequence in the Magnesia region of central Greece. Geophysical J.R. Astron. Society, 75, 155-168, 1983.

Papazachos B., Papazachou K. 1989. Earthquakes in Greece, Thessaloniki, Greece. 